\section{Rose Phytoene Desaturase Gene Silencing by Apple Latent Spherical Virus Vectors}

\author{
Hiroaki Ito ${ }^{1}$, Masaki Ochiai, Hiroaki Kato, Katsuhiro Shiratake, \\ Daigo Takemoto, Shungo Otagaki, and Shogo Matsumoto ${ }^{2}$ \\ Graduate School of Bioagricultural Sciences, Nagoya University, Chikusa, \\ Nagoya 464-8601, Japan
}

Additional index words. Rosa rugosa, Rosa multiflora, PTGS, photo-bleached phenotype

\begin{abstract}
We have succeeded in establishing a virus-induced gene silencing (VIGS) of rose using Apple latent spherical virus (ALSV) vectors. An ALSV infection on rose did not cause any symptoms like those observed on other plant species and grew healthy. We have cloned and sequenced the phytoene desaturase (PDS) gene in wild rose, then used its fragment for silencing the rose internal $P D S$ gene. The silencing phenotypes such as the highly uniform photo-bleached phenotype with PDS inhibitions were observed on the upper leaves of primary shoots and on a secondary shoot of $\boldsymbol{R}$. rugosa for more than 5 months. ALSV vectors seemed useful for analyzing gene function and for the molecular breeding of rose.
\end{abstract}

Roses are one of the economically most important ornamental plants, and modern commercial roses consisting of several thousand cultivated varieties are found widespread around the world. Because consumers always expect new varieties with high ornamental value such as flowers of a new shape and color, breeders and breeding companies are continuously producing new varieties by cross-hybridization and/or mutation breeding techniques. However, because only eight to 10 species among more than 150 have contributed to modern commercial roses (Matsumoto et al., 1998), it has become difficult to produce new epoch-making varieties because their genetic background is limited.

A genetically modified blue rose was introduced into the market in 2011 (Katsumoto et al., 2007). Because roses have no blue varieties because of the absence of the flavonoid $3^{\prime}, 5^{\prime}$-hydroxylase $\left(F^{\prime} 5^{\prime} H\right)$ gene, which is essential to synthesizing the delpphinidinebased anthocyanins, a transgenic blue rose has been produced by the expression of an introduced pansy $\mathrm{F3}^{\prime} \mathrm{5}^{\prime} \mathrm{H}$ gene (Katsumoto et al., 2007; Tanaka and Omiya, 2008). Besides the $F 3^{\prime} 5^{\prime} H$ gene producing the blue rose, the introduction of an Ace-AMP1 and basic (Class 1) chitinase gene caused resistance to powdery mildew and blackspot, respectively, and the rooting ability of rose was

Received for publication 29 May 2012. Accepted for publication 13 July 2012 .

This research was supported by a Grant-in-Aid for KAKENHI (no. 23658026).

We thank Dr. Nobuhiro Yoshikawa, Dr. Koji Kawamura, and Dr. Kunio Yamada for their useful suggestions.

${ }^{1}$ Present address: Kewpie Egg Corporation, 2-5, SENGAWA-CHO, CHOFU-SHI, Tokyo, 182-0002, Japan.

${ }^{2}$ To whom reprint requests should be addressed; e-mailshogo@agr.nagoya-u.ac.jp. enhanced by the introduction of a $R O L$ gene from Agrobacterium rhizogenes (Marchant et al., 1998a, 1998b; van der Salm et al., 1997). However, such traits proved unattractive to consumers as did other genetically modified roses introducing the reporter or marker genes such as the $\beta$-glucuronidase gene, luciferase gene, neomycin phosphotransferase gene, and green fluorescent protein gene (Firoozabady et al., 1994; Kim et al., 2004; Li et al., 2002, 2003; Vergne et al., 2010). These agrobacterium-mediated genetic or biolistic transformation systems require much effort as a result of their low efficiency of transformation and also need a long timespan for making and keeping the somatic embryos and the generation of transgenic plants. Moreover, because many rose varieties are known to be recalcitrant to regeneration and hence to genetic transformation, somatic embryos of limited rose varieties such as 'Royalty', 'Carefree Beauty', 'Tineke', 'Glad Tidings', 'Moneyway' and 'Old Blush' were used as sources for genetic transformation (Firoozabady et al., 1994; Kim et al., 2004; Li et al., 2002, 2003; Marchant et al., 1998a, 1998b; van der Salm et al., 1997; Vergne et al., 2010). Because all the varieties used (except for 'Old Blush') are tetraploid, they are not useful for studying the gene function in rose for complicated dose effects among alleles.

Recently, although we have established a plantlet regeneration system of the diploid wild rose, Rosa rugosa, we could not succeed in its genetic transformation, probably as a result of its low transformation frequency (Matsumoto, 2009). R. rugosa distributed throughout northern Japan has contributed to the development of some modern commercial roses, including hybrid rugosas, hybrid kordesii, and shrub roses (Cairns, 2000). This species possesses unique and valued traits, including large fragrant flowers, a long flowering period, disease resistance, and winterhardiness (Svejda, 1974, 1977). It is one of the few recurrently flowering species, which has been critically important to establishing its widespread use in the ornamental trade.

VIGS is a powerful tool for the fast and efficient functional analysis of genes in plants (Burch-Smith et al., 2004; Purkayastha and Dasgupta, 2009; Robertson, 2004). Because VIGS circumvents the plant transformation system, it might be possible to use it for rose varieties that are hard to transform. An ALSV of $\approx 25$-nm diameter particles belonging to the genus Cheravirus contains two singlestranded RNA species (RNA 1 and RNA 2) and three capsid proteins (Vp25, Vp20, and Vp24) (Li et al., 2000). It consists of two components, $\mathrm{M}$ and $\mathrm{B}$, containing two molecules of RNA 2 and a single molecule of RNA 1, respectively (Li et al., 2000). RNA 1 and RNA 2 of 6813 nt and 3385 nt length, respectively, excluding the $3^{\prime}$ poly(A) tail, have a single open reading frame encoding to a replication-associated protein of $243 \mathrm{~K}$ and a $42 \mathrm{KDa}$ movement protein on the Nterminal side and three capsid proteins on the C-terminal side, respectively (Li et al., 2000; Yoshikawa et al., 2006). Recently, a VIGS vector based on ALSV has been developed that succeeded in silencing endogenous genes such as $P D S$, magnesium chelatase, a ribulose1,5-bisphosphate carboxylase small subunit, an alpha subunit of chloroplast chaperonin, an elongation factor 1 , a terminal flower 1 , and an isoflavone synthase in a broad range of plants including tobacco, tomato, Arabidopsis, cucurbits, legumes, apple, pear, and Japanese pear (Igarashi et al., 2009; Sasaki et al., 2011). Moreover, the ALSV-based vector expressing a FLOWERING LOCUS $T$ gene has induced rapid flowering in apple, suggesting that the vector might enter and replicate in the meristematic tissue of apple trees (Yamagishi et al., 2011).

In this study, as a first step for developing a functional analysis of genes in rose and a new breeding system in rose, we investigated the availability of ALSV vectors in rose.

\section{Materials and Methods}

Plant materials. Wild roses (Rosa rugosa Thunb. ex Murray, R. multiflora Thunb. ex Murray, and $R$. bracteata Wendl.) were grown in a field at the Experimental Farm of the Graduate School of Bioagricultural Sciences, Nagoya University, Japan. Young leaves were collected, frozen dry at $-80{ }^{\circ} \mathrm{C}$, and stored until use. Their seeds were stored at $4{ }^{\circ} \mathrm{C}$, and germinated seedlings with one to three true leaves were used for further experiments.

Construction of ALSV vectors and viral inoculation. Total RNAs of $R$. multiflora leaves were extracted essentially as described by Chang et al. (1993), and reverse transcription was performed with Oligo (dT) using the RNA $\mathrm{PCR}^{\mathrm{TM}}$ kit (AMV) Version 3.0 (TAKARA BIO Inc., Shiga, Japan) according to the manufacturer's instructions. To clone the rose PDS gene, we used Rosa PDS-F (5' -TGGCA 
GATGCAGGTCATAAA-3' ${ }^{\prime}$ ) and tPDS-R $\left(5^{\prime}\right.$-CTTCAGTTTTCTGTCAAACC-3') as forward and reverse primers from alignment sequences of the PDS genes in $R$. $\times$ hybrida (FJ853597.1), Nicotiana tabacum (AJ616742.1), and Fragaria $\times$ ananassa (FJ795342.1). A fragment of $\approx 900$ bp corresponding to the R. multiflora ortholog of PDS (mulPDS) was amplified by polymerase chain reaction using the primers as mentioned, and PrimeSTAR ${ }^{\mathrm{R}}$ GXL DNA Polymerase (TAKARA BIO Inc., Shiga, Japan) under the following conditions: 35 cycles of $10 \mathrm{~s}$ at $98^{\circ} \mathrm{C}, 15 \mathrm{~s}$ at $55^{\circ} \mathrm{C}, 1 \mathrm{~min}$ at $68^{\circ} \mathrm{C}$, and a final extension of $7 \mathrm{~min}$ at $72{ }^{\circ} \mathrm{C}$. The fragment was cloned using the DNA ligation Kit $<$ Mighty Mix $>$ and/or the Mighty TA-cloning Kit (TAKARA BIO Inc., Shiga, Japan). The sequences of the positive clones were then determined by dideoxy chain termination on an Applied Biosystems 3130 Genetic analyzer (Life Technologies Japan Co., Ltd.) using a Big Dye Terminator Version 3.1 Cycle Sequencing Kit (Life Technologies Japan Co., Ltd.).

A 162-bp fragment corresponding to the nucleotide positions $189-351$ of the mulPDS gene was amplified from $R$. multiflora cDNAs obtained by RT with Oligo (dT) by PCR using the XhoI-RmPDS-F (5'-GAACTCGAGCCA AACAAGCCAGGAGAGTT- $\overline{3}^{\prime}$ ), including the XhoI site (underlined), and the BamHIRmPDS-R (5'-AAGGATCCAGCCTGTCC

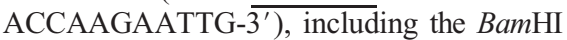
site (underlined) as forward and reverse primers, respectively, for making the mulPDS-ALSV vector. The PCR was carried out with KOD-Plus-Ver.2 DNA polymerase (TOYOBO Co., Ltd., Osaka, Japan) under the following conditions: 2 min at $94{ }^{\circ} \mathrm{C}, 30$ cycles of $10 \mathrm{~s}$ at $98^{\circ} \mathrm{C}, 30 \mathrm{~s}$ at $54^{\circ} \mathrm{C}, 30 \mathrm{~s}$ at $68^{\circ} \mathrm{C}$, and a final extension of $7 \mathrm{~min}$ at $72{ }^{\circ} \mathrm{C}$. The fragment corresponding to the $162 \mathrm{bp}$ was cloned and sequenced as mentioned, and the 162-bp fragment was obtained by $\mathrm{XhoI}$ and $\mathrm{BamHI}$ double digestion at $37^{\circ} \mathrm{C}$ for $2 \mathrm{~h}$ and then ligated to the BamHI-XhoI sites of the pEALSR2-based vector ( $\mathrm{Li}$ et al., 2004). We have named the vector pEALSR2L5R5mulPDS. Chenopodium quinoa plants were wounded and inoculated with combinations of two cDNA infectious clones comprising the viral genome (pEALSR1 and pEALSR2L5R5, pEALSR1 and pEALSR2L5R5-mulPDS) using a mechanical method (Li et al., 2004). After 2 to 3 weeks, leaves with symptoms of viral infection were crushed in three volumes of extraction buffer $(0.1 \mathrm{M}$ Tris- $\mathrm{HCl}, \mathrm{pH} 7.8$, $1 \mathrm{~mm}$ EDTA) and then the crude extract containing viral RNA was reinoculated to the $C$. quinoa plants. Total RNAs were purified from infected $C$. quinoa leaves using a TRIzol reagent (Life Technologies Japan Ltd., Tokyo, Japan) and then adsorbed onto gold particles as follows. Fifteen milligrams of gold particles $(1.0 \mu \mathrm{m}$ in diameter; Bio-Rad Laboratory, Inc., CA) was sonicated in RNase-free distilled water $(50 \mu \mathrm{L})$ for at least $1 \mathrm{~min}$ using the ULTRASONIC CLEANER VS-F100 (As One Co., Ltd., Osaka, Japan). After 5 min shaking of gold particles with $150 \mu \mathrm{L}$ of total RNA extracted from infected leaves $(150 \mu \mathrm{g}), 45 \mu \mathrm{L}$ of $5 \mathrm{M}$ ammonium acetate was added and shaken for $5 \mathrm{~min}$ and then $990 \mu \mathrm{L}$ of 2-propanol was added and shaken for $5 \mathrm{~min}$. The mixture was placed at $-20{ }^{\circ} \mathrm{C}$ for at least $1 \mathrm{~h}$. Gold particles coated with total RNAs were washed three times with $1.0 \mathrm{~mL}$ of ethanol $(99.5 \%)$ and resuspended in an appropriate amount $(\approx 1.8 \mathrm{~mL})$ of ethanol $(99.5 \%)$. The suspension was used for preparing the gold-coat tubing according to the manufacturer's instructions. The tube coated with gold particles was cut into 30 cartridges, each containing $5 \mu \mathrm{g}$ of total RNAs from infected leaves. The rose seedlings were bombarded with two shots per seedling using gold particles coated with total RNSs at 1650 psi pressure using the PDS-1000/HeTM Particle Delivery System (Bio-Rad Laboratory, Inc.) or 80-100 psi pressure using the Helios Gene Gun System (Bio-Rad Laboratory, Inc.). After particle bombardment, the plants inoculated wtALSV or ALSV vectors were grown in a growth chamber BIOTRON (Nippon Medical and Chemical Instruments Co. Ltd., Tokyo, Japan) and set at $23{ }^{\circ} \mathrm{C}$ under long-day conditions (16 h light, $8 \mathrm{~h}$ dark).

RNA analyses. Total RNAs of the newly generated upper leaves after inoculation of wtALSV or ALSV vector on rose seedlings were extracted using the kit RNA-suisui-R (Rizo, Co., Ltd., Tsukuba, Japan) according to the manufacturer's instructions. The first strand of cDNA was synthesized using PrimeSTAR $^{\mathrm{R}}$ GXL DNA Polymerase (TAKARA BIO Inc., Shiga, Japan). Then the wtALSV and mulPDSALSV fragments were amplified by PCR using pEALSR2-F (5'-ACTATGCCA CTGAACATGCG-3'; nucleotide position 1314-1333) and pEALSR2-R (5'-GGGCA AATGGAAACAGTCTC-5' ; nucleotide position 1548-1567) as forward and reverse primers derived from the sequence of ALSV RNA2 (AB030941.1; Li et al., 2000). The PCR was conducted with DNA polymerase in an EmeraldAmp PCR Master Mix (TAKARA BIO Inc., Shiga, Japan) under the following conditions: 2 min at $94{ }^{\circ} \mathrm{C}, 30$ cycles of $10 \mathrm{~s}$ at $98^{\circ} \mathrm{C}, 30 \mathrm{~s}$ at $54{ }^{\circ} \mathrm{C}, 30 \mathrm{~s}$ at $68^{\circ} \mathrm{C}$, and a final extension of $7 \mathrm{~min}$ at $72^{\circ} \mathrm{C}$. Expression analyses of the $P D S$ gene in silenced rose leaves were carried out by semiquantitative reverse transcriptase-PCR using the Rosa PDS-F and

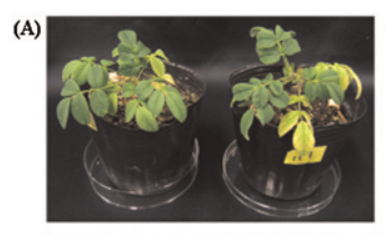

(C)
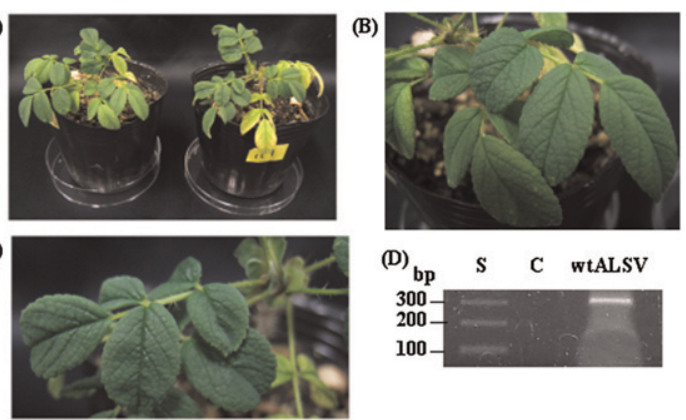

Fig. 1. Rose (Rosa rugosa) plants inoculated with wtALSV. (A) Left: control (no inoculation), $260 \mathrm{~d}$ after sowing; right: wtALSV inoculation, $240 \mathrm{~d}$ after inoculation. (B) Leaves of control. (C) Leaves of wtALSV inoculation. (D) Detection of polymerase chain reaction fragment corresponding to $302 \mathrm{bp}$, derived from wtALSV at a newly generated upper leaf $175 \mathrm{~d}$ after inoculation. $\mathrm{S}=$ size marker; $\mathrm{C}=$ control (no inoculation).
Rosa PDS-R (5'-ATCCCCTGTTTTCTCA TCC $\left.-3^{\prime}\right)$ as forward and reverse primers, respectively. PCR amplifications were performed with DNA polymerase in an EmeraldAmp PCR Master Mix (TAKARA BIO Inc.) under the following conditions: $2 \mathrm{~min}$ at $94{ }^{\circ} \mathrm{C}, 29,30,31$ cycles of $10 \mathrm{~s}$ at $98^{\circ} \mathrm{C}, 30 \mathrm{~s}$ at $55^{\circ} \mathrm{C}, 30 \mathrm{~s}$ at $72^{\circ} \mathrm{C}$, and a final extension of $7 \mathrm{~min}$ at $72{ }^{\circ} \mathrm{C}$. The Rosa $\times$ hybrida $\beta$-actin gene was used as the internal control (Mibus et al., 2011).

\section{Results and Discussion}

Inoculation of wtALSV to rose. To use ALSV vectors for gene silencing of the endogenous genes in rose, we first inoculated wtALSV to wild rose at several seedling stages. In apple, the cotyledons of seeds just after germination are regarded as the most effective tissues for performing efficient ALSV inoculation (Sasaki et al., 2011). However, it seemed to be difficult to use that stage in rose because its cotyledons are more sensitive to mechanical damage compared with those of apple. Actually, most seedlings stopped growing after particle bombardments of total RNAs from C. quinoa, including the RNAs of wtALSV. Finally, using the stage of $R$. rugosa and $R$. multiflora seedlings as the second or third true leaf appeared for particle bombardments, we succeeded in detecting a PCR fragment corresponding to the expected length of $302 \mathrm{bp}$ using primers specific for ALSV RNA2 from the upper leaf of one of 12 R. rugosa and none of $10 R$. multiflora used (Table 1; Fig. 1). We could find no obvious

Table 1. Ratio of ALSV infection in rose species.

\begin{tabular}{llc}
\hline Virus vectors & \multicolumn{1}{c}{ Species } & $\begin{array}{c}\text { Number of infected } \\
\text { plants }^{\mathrm{z}} / \text { total plants }\end{array}$ \\
\hline wtALSV & $R$. rugosa & $1 / 12$ \\
mulPDS-ALSV & $R$. multiflora & $0 / 11$ \\
& $R$ rugosa & $4^{\mathrm{y} / 71}$ \\
& $R$. bracteata & $0 / 48$ \\
\hline
\end{tabular}

${ }^{\mathrm{z}}$ Successful infection of the virus in rose species was estimated by reverse transcription-polymerase chain reaction analysis.

${ }^{\mathrm{y}}$ Conditions of psi pressure at bombardment is 80 psi (one plant) or 100 psi (three plants).

$\mathrm{ALSV}=$ Apple latent spherical virus. 
symptoms on either inoculate or upper leaves of $R$. rugosa, and they grew healthy as observed in ALSV-infected plants of the family Amaranthaceae, Braccicaceae, Leguminaceae, Scrophulariaceae, and Solanaceae (Igarashi et al., 2009). Based on those results, we thought that ALSV could infect rose without symptoms.

Cloning of the PDS gene from rose and $P D S$ fragment for silencing. Because PDS is one of the widely used VIGS markers, we tried to silence the $P D S$ gene in rose. We have cloned and determined a 838-bp cDNA sequence of the $P D S$ gene in R. multiflora (deposited under the accession number AB705444), because only $491 \mathrm{bp}$ of that in $R$. $\times$ hybrida was available on the database. We compared the cDNA sequence with that of $R . \times$ hybrida at the corresponding region and clarified a $97.8 \%$ and a $98.0 \%$ similarity at nucleotide and a deduced amino acid level, respectively. We searched the $P D S$ region showing completely identical sequences between that in R. multiflora and in R. $\times$ hybrida for inducing the PDS silencing for different wild roses. Because the ALSV vectors carrying $\approx 200 \mathrm{bp}$ PDS sequences induced the stable VIGS efficiently in Nicotiana species (Igarashi et al., 2009), we have selected the $162 \mathrm{bp}$ (54 deduced amino acids) cDNA fragment having identical sequences.

Virus-induced silencing of PDS gene in the seedlings of rose. The 162-bp fragment of the $P D S$ gene in rose was inserted into an ALSV-RNA2-based vector (Fig. 2). The resulting virus was designated as pEALSR2L5R5mulPDS (mulPDS-ALSV), and total RNAs isolated from mulPDS-ALSV-infected $C$. quinoa leaves were inoculated to the 71 $R$. rugosa and $48 R$. bracteata seedlings because the stage of the second true leaf appeared by particle bombardments. We observed a photo-bleached phenotype in four independent seedlings of $R$. rugosa, and the ratio of mulPDS-ALSV infection was 5.6\% (Table 1). The first one showed the photo-bleached phenotype as a fourth true compound leaf $16 \mathrm{~d}$ after inoculation (Fig. 3). The photobleached phenotype continued to the eighth true compound leaf and stopped the growing. We obtained a PCR fragment corresponding to the expected length of $464 \mathrm{bp}$ using primers specific for mulPDS-ALSV RNA2 from both of the third (green) and fourth (white) true leaves (Fig. 3). We investigated the expression level of the $P D S$ gene in the third to sixth true leaves of the seedling infected with mulPDS-ALSV by semiquantitative PCR using their total RNAs (Fig. 4A). The levels of the $P D S$-mRNA were distinctly reduced at the fourth to sixth white leaves of the seedling infected with mulPDS-ALDV compared with those in both non-infected and wtALSV-infected healthy leaves. Because the $P D S$ gene is essential for the production of carotenoid pigments, the phenotype seemed to be typical for silencing of the PDS. The levels of PDS expression at the third green leaf were not strikingly reduced as were those observed in the fourth to sixth white leaves despite mulPDS-ALSV detection in the third green leaf. ALSV expressing

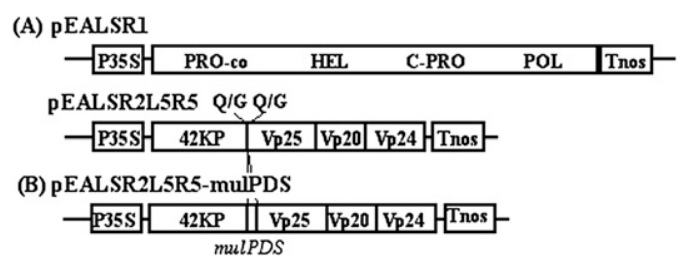

Fig. 2. Structure of apple latent spherical virus (ALSV) vectors. (A) Infectious cDNA clones of ALSVRNA1 (pEALSR1) and ALSV-RNA2 vector (pEALSR2L5R5) with artificial processing sites by duplicating the $\mathrm{Q} / \mathrm{G}$ cleavage site between $42 \mathrm{KP}$ and VP 25. (B) The 162-bp PDS fragment from $R$. multiflora (mulPDS) was inserted between $42 \mathrm{KP}$ and VP25 using XhoI and BamHI restriction sites (pEALSR2L5R5-mulPDS). P35S = CaMV 35S promoter; Tnos = nopaline synthase terminator; PRO$\mathrm{co}=$ protease cofactor; $\mathrm{HEL}=\mathrm{NTP}$-binding helicase; $\mathrm{C}-\mathrm{PRO}=$ cysteine protease; $\mathrm{POL}=\mathrm{RNA}$ polymerase; $42 \mathrm{KP}=42 \mathrm{~K}$ movement protein; Vp25, Vp20, and Vp24 = capsid proteins. PDS = phytoene desaturase.

(A)

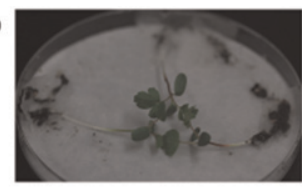

(C)

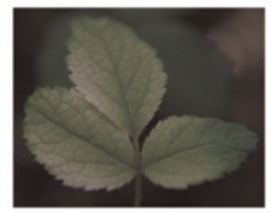

(B)
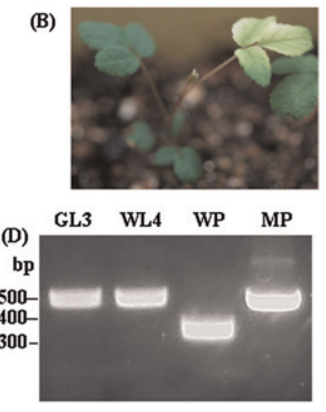

Fig. 3. Silencing of the PDS gene in Rosa rugosa primary shoot. (A) R. rugosa seedlings used for infection. (B-C) R. rugosa seedling infected with pEALSR2L5R5-mulPDS (mulPDS-ALSV). The photobleached phenotype was observed on newly generated fourth leaves $16 \mathrm{~d}$ after inoculation. (D) Detection of a polymerase chain reaction fragment corresponding to $464 \mathrm{bp}$ derived from pEALSR2L5R5-mulPDS. GL3 = third true leaf (green); WL4 = fourth true leaf (white); WP = pEALSR2L5R5 (wtALSV) plasmid DNA; MP = pEALSR2L5R5-mulPDS (mulPDS-ALSV) plasmid DNA.

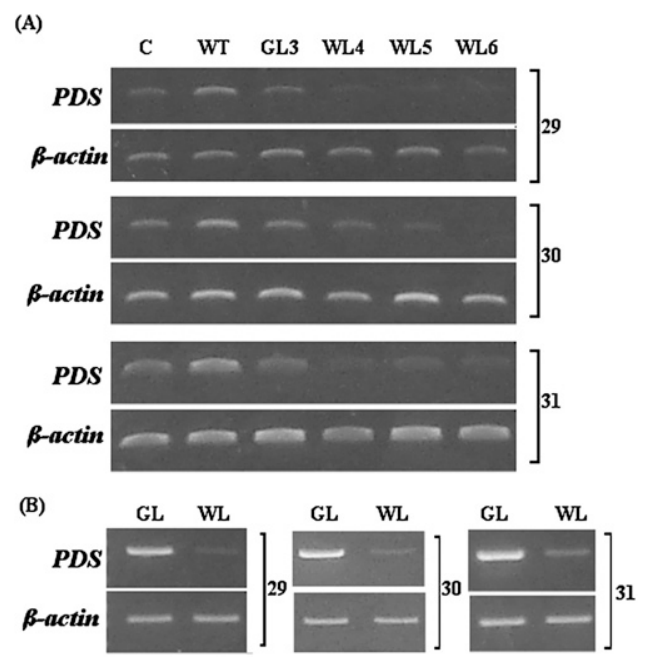

Fig. 4. Expression analyses of PDS gene in Rosa rugosa primary and secondary shoots. Semiquantitative reverse transcription-polymerase chain reaction (PCR) analyses of phytoene desaturase and $\beta$-actin gene in the leaves of $R$. rugosa primary (A) and secondary shoots (B). 29-31 represents a PCR cycle number. $\mathrm{C}=$ control (no inoculation); WT, wtALSV inoculation; GL3, third true leaf (green) from primary shoot; WL4 = fourth true leaf (white) from primary shoot; WL5 = fifth true leaf (white) from primary shoot; WL6 = sixth true leaf (white) from primary shoot; GL = green leaf from secondary shoot; WL = photo-bleached leaf from secondary shoot.

green fluorescent protein (GFP-ALSV) infection on transgenic tobacco expressing GFP (GFP-tobacco) at the third to fifth true leaves of the sixth true leaf stage induced VIGS at the 10th to 12th leaves (Yaegashi et al., 2007). Based on those results, the amount of mulPDSALSV seemed to be insufficient for VIGS at the stage of third green leaf generation. The 

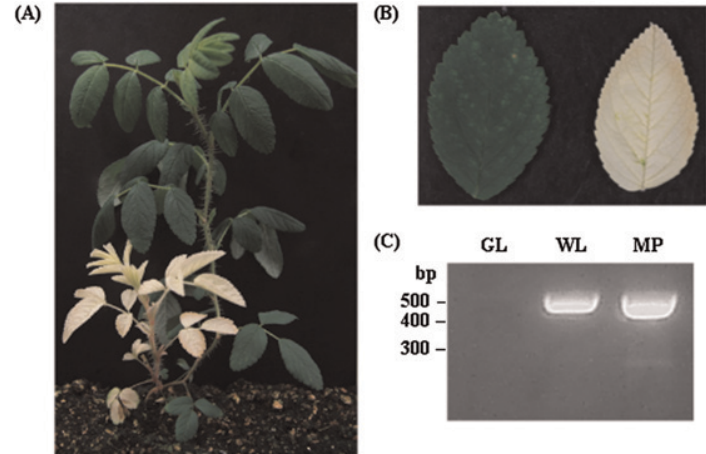

Fig. 5. Silencing of PDS gene in Rosa rugosa secondary shoot. (A) Photo-bleached secondary shoot developed from axillary bud of primary shoot obtained by infection of mulPDS-ALSV to $R$. rugosa seedling. (B) Left, green leaf of primary shoot; right, photo-bleached leaf of secondary shoot. (C) Detection of polymerase chain reaction fragment corresponding to $464 \mathrm{bp}$ derived from pEALSR2L5R5-mulPDS. GL = green leaf from primary shoot; $\mathrm{WL}=$ photo-bleached leaf from secondary shoot; MP = pEALSR2L5R5-mulPDS (mulPDS-ALSV) plasmid DNA.

second and third seedlings also showed the photo-bleached phenotypes at the fifth true compound leaf after 14 and $16 \mathrm{~d}$ from inoculation, respectively (data not shown). These seedlings also stopped growing, probably as a result of a scarcity of nutrients caused by insufficient photosynthesis. One died at the fifth stage of true leaf expansion, but the photo-bleached leaves of the other one turned green, then started re-growing after 1 month, and newly generated leaves also showed a photo-bleached phenotype (data not shown). The fourth seedling exhibited the most severe phenotype (Fig. 4). Although the primary shoot showed no photo-bleached phenotype, the secondary shoot derived from the base of the second true leaf showed a completely photo-bleached phenotype. The secondary shoot began growing at the stage of the eighth true leaf's appearance on a primary shoot, whereas the photo-bleached phenotype continued growing for more than 5 months. We have detected a PCR fragment corresponding to the expected length of 464 bp using primers specific for mulPDS-ALSV RNA2 from the white leaves of a second shoot but not detected from the green leaves of a primary shoot (Fig. 5). The expression levels of the $P D S$ gene were distinctly reduced at the white leaves of the secondary shoot compared with those in the green leaves of the primary shoot (Fig. 4B). Thus, we speculated that an infection of mulPDSALSV occurred in the axially bud existing at the base of the second true leaf. Actually, ALSV propagated at the host cells moved to adjacent cells through plasmodesmata and then caused a systemic infection including meristems (Sasaki et al., 2011; Yamagishi et al., 2011). Because the photosynthesis of a photo-bleached secondary shoot might be reduced compared with that of a green primary shoot, the direction of translocation within the phloem seemed to be from a primary to a secondary shoot. Thus, mulPDSALSV propagated in the secondary shoot did not move into the primary shoot. A tertiary shoot derived from a secondary shoot also showed a photo-bleached phenotype (data not shown).
In the present study, we demonstrated that the ALSV vector could act as an inducer for the silencing of the endogenous gene in rose. One advantage of ALSV-mediated VIGS in rose is that ALSV infects rose without showing any symptoms. This may be preferable depending on the phenotype of the target gene. On the other hand, at present it is necessary to bombard a large amount of rose seedlings as a result of the low efficiency of the ALSV infection. Although we have not succeeded in inoculating onto cotyledons of germinated rose seeds, it might be possible to develop a particle bombardment procedure optimized for those tissues by changing the bombardment pressure or gold particle size. Also, because susceptibility to virus could be different between species or genotypes, it is worth testing whether other genus Rosa and/or genotypes of $R$. rugosa show improved infection efficiency. Nonetheless, our VIGS-inducing system in rose reported here might be a powerful tool for functional validation of genes associated with horticulturally important traits such as flower morphology, recurrent flowering, and density or number of thorns.

\section{Literature Cited}

Burch-Smith, T., J.C. Anderson, G.B. Martin, and S.P. Dinesh-Kumer. 2004. Application and advantages of virus-induced gene silencing for gene function studies in plants. Plant J. 39:734-746.

Cairns, T. 2000. Modern roses XI, The world encyclopedia of roses. Academic Press, San Diego, CA.

Chang, S., J. Puryear, and J. Cairney. 1993. A simple and efficient method for isolating RNA from pine trees. Plant Mol. Biol. Rpt. 11:113-116.

Firoozabady, E., Y. Moy, N. Courtney-Gutterson, and K. Robinson. 1994. Regeneration of transgenic rose (Rosa hybrida) plants from embryogenic tissue. Bio/technology 12:609-613.

Igarashi, A., K. Yamagata, T. Sugai, Y. Takahashi, E. Sugawara, A. Tamura, H. Yaegashi, N. Yamagishi, T. Takahashi, M. Isogai, H. Takahashi, and N. Yoshikawa. 2009. Apple latent spherical virus vectors for reliable and effective virusinduced gene silencing among a broad range of plants including tobacco, tomato, Arabidopsis thaliana, cucurbits, and legumes. Virology 386:407-416.
Katsumoto, Y., M. Fukunishi-Mizukami, Y. Fukui, F. Brugliera, T.A. Holton, M. Karan, N. Nakamura, K. Yonekura-Sakakibara, J. Togami, A. Pigeaire, G.-Q. Tao, N.S. Nehra, C.-Y. Li, B.K. Dyson, S. Tsuda, T. Ashikari, T. Kusumi, J.G. Mason, and Y. Tanaka. 2007. Engineering of the rose flavonoid biosynthetic pathway successfully generated blue-hued flowers accumulating delphinidin. Plant Cell Physiol. 48:1589-1600.

Kim, C.K., J.D. Chung, S.H. Park, A.M. Burrell, K.K Kamo, and D.H. Byrne. 2004. Agrobacterium tumefaciens-mediated transformation of Rosa hybrida using the green fluorescent protein (GFP) gene. Plant Cell Tissue Organ Cult. 78:107-111

Li, C., N. Sasaki, M. Isogai, and N. Yoshikawa. 2004. Stable expression of foreign proteins in herbaceous and apple plants using Apple latent spherical virus RNA2 vectors. Arch. Virol. 149:1541-1558

Li, C., N. Yoshikawa, T. Takahashi, T. Ito, K. Yoshida, and H. Koganezawa. 2000. Nucleotide sequence and genome organization of Apple latent spherical virus: A new virus classified into the family Comoviridae. J. Gen. Virol. 81:541-547.

Li, X., K. Gasic, B. Cammue, W. Broekaert, and S.S. Korban. 2003. Transgenic rose lines harboring an antimicrobial protein gene, Ace$A M P 1$, demonstrate enhanced resistance to powdery mildew (Sphaerotheca pannosa). Planta 218:226-232.

Li, X., S.F. Krasnyanski, and S.S. Korban. 2002 Optimization of the uidA gene transfer into somatic embryos of rose via Agrobacterium tumefaciens. Plant Physiol. Biochem. 40:453-459.

Marchant, R., J.B. Power, J.A. Lucas, and M.R. Davey. 1998a. Biolistic transformation of Rose (Rosa hybrida L.). Ann. Bot. (Lond.) 81:109114.

Marchant, R., M.R. Davey, J.A. Lucas, C.J. Lamb, R.A. Dixon, and J.B. Power. 1998b. Expression of a chitinase transgene in rose (Rosa hybrida L.) reduces development of blackspot disease (Diplocarpon rosae Wolf). Mol. Breed. 4:187194.

Matsumoto, S. 2009. Plantlet regeneration via organogenesis from immature seeds of Rosa rugosa Thunb. ex. Murray. Floriculture Ornamental Biotech. 3:86-88.

Matsumoto, S., M. Kouchi, J. Yabuki, M. Kusuniki, Y. Ueda, and H. Fukui. 1998. Phylogenetic analyses of the genus Rosa using the matK sequence: Molecular evidence for the narrow genetic background of modern roses. Sci. Hort. 77:73-82.

Mibus, H., D. Heckl, and M. Serek. 2011. Cloning and characterization of three APETALA1/ FRUITFULL-like genes in different flower types of Rosa $\times$ hybrida L. J. Plant Growth Regul. 30:272-285.

Purkayastha, A. and I. Dasgupta. 2009. Virusinduced gene silencing: A versatile tool for discovery of gene functions in plants. Plant Physiol. Biochem. 47:967-976.

Robertson, D. 2004. VIGS vectors for gene silencing: Many targets, many tools. Annu. Rev. Plant Biol. 55:495-519.

Sasaki, S., N. Yamagishi, and N. Yoshikawa. 2011. Efficient virus-induced gene silencing in apple, pear and Japanese pear using Apple latent spherical virus vectors. Plant Methods 7:15

Svejda, F. 1974. Reproductive capacity of $F_{1}$ hybrids from Rosa rugosa and chinensis cultivars. Euphytica 23:665-669.

Svejda, F. 1977. Breeding for improvement of flowering attributes of winter hardy Rosa rugosa hybrids. Euphytica 26:697-701. 
Tanaka, Y. and A. Omiya. 2008. Seeing is believing: Engineering anthocyanin and carotenoid biosynthetic pathways. Curr. Opin. Biotechnol. 19:190-197.

van der Salm, T.P.M., C.J.G. van der Toorn, R. Bouwer, C.H. Hanisch ten Cate, and H.J.M. Dons. 1997. Production of ROL gene transformed plants of Rosa hybrida L. and characterization of their rooting ability. Mol. Breed. 3:39-47.

Vergne, P., M. Maene, G. Gabant, A. Chauvet, T. Debener, and M. Bendahmane. 2010. Somatic embryogenesis and transformation of the diploid Rosa chinensis cv Old Blush. Plant Cell Tissue Organ Cult. 100:73-81.

Yaegashi, H., T. Yamatsuta, T. Takahashi, C. Li, M. Isogai, T. Kobori, S. Ohki, and N. Yoshikawa. 2007. Characterization of virus-induced gene silencing in tobacco plants infected with Apple latent spherical virus. Arch. Virol. 152:1839-1849.

Yamagishi, N., S. Sasaki, K. Yamagata, S. Komori, M. Nagase, M. Wada, T. Yamamoto, and N. Yoshiwaka. 2011. Promotion of flowering and reduction of a generation time in apple seedlings by ectopical expression of the Arabidopsis thaliana FT gene using the Apple latent spherical virus vector. Plant Mol. Biol. 75: 193-204.

Yoshikawa, N., K. Okada, K. Asanuma, K. Watanabe, A. Igarashi, C. Li, and M. Isogai. 2006. A movement protein and three capsid proteins are all necessary for the cell-to-cell movement of Apple latent spherical cheravirus. Arch. Virol. 151:837848. 